\title{
Why Designers Do a PhD?
}

\author{
Anirudha Joshi \\ IIT Bombay \\ Mumbai 400076, India \\ anirudha@iitb.ac.in
}

\begin{abstract}
PhD programmes in design seem to be becoming increasingly popular though questions about design research have been raised. In this paper I present a short survey that I did with designers from India, who either have done a PhD in design or are doing one. An online questionnaire was circulated among 34 design researchers. Twenty responded. As expected, the PhD has improved their ability to do research. The impact on ability to do design and impact on salaries seems to be mixed. Among the reasons for starting to do a PhD, opinion was divided about a PhD helping improve job prospects in the industry and even more divided about it being a requirement in academic institutions. But why do designers do a PhD then? The reasons are interest in the area of their PhD, because it will help them grow as a person and because they are interested in research. PhDs have helped people become a better researcher, a better design teacher and also a better person but it has not helped them become a better designer.
\end{abstract}

Design, designers, research, PhD.

\section{INTRODUCTION}

Interest in design research is not new. Early work in design research in the 1950s borrowed from techniques in operational research to develop "systematic methods of problem solving, borrowed from computer techniques and management theory, for the assessment of design problems and the development of design solutions" (Archer, 1965). Importance of research in the context of design has also been acknowledged. Bonsiepe says that compared with other domains, design is a scandalously under-researched field and that a profession which does not foster and promote research intensively, has no future (Bonsiepe, 2000).

Design research stayed a controversial matter and there are several views about what constitutes design research. Technical rationality has also been challenged and importance was given to the implicit in the artistic, intuitive processes which practitioners bring "to situations of uncertainty, instability, uniqueness and value conflict" (Schön, 1983). Newbury feels that the difference between research in design and research in other disciplines is often over-stressed and calls for a dialogue with disciplines with which design has overlapping interests (Newbury, 2002).

We can't even say that design has established its typical criteria for research. Jones expresses doubts that anyone has yet found a definition of design research "that does not risk excluding or inhibiting imaginative work for the sake of academic respectability and reputation" (Jones, et al., 1998). Cross suggests that our concern in design research has to be the "development, articulation and communication of design knowledge" that we can look for in people, processes and products (Cross, 2007).

In spite of popular belief that designers don't read, articulation of design thinking also has a long enough history. Journals related to design have been published for several years. Visible Language (originally published as the Journal of Typographical Research) (1967), U\&lc (1973), Design Studies (1979) and Design Issues (1984) are some of the well known examples of journals running for a long time. The importance of design research and articulation continued to grow and diversify as design entered more domains. Apart from design-specific journals and conferences, several domain-specific journals and conferences (such as those related to $\mathrm{HCl}$ and interaction design) also have been carrying peer-reviewed research publications and conferences for several years. Further, such articulation is not restricted to refereed and edited material alone. High-quality articulation can also be found online. PhD Design a popular mailing list on discussion of PhD studies and related research in design has been active since 1998 (1998). There are several blogs and other online media for articulation - for example (Ranjan, 2009). 
The popularity of $\mathrm{PhD}$ programmes in design has been a fairly recent phenomenon world over. For example, Institute of Design, IIT Chicago, one of the older PhD programmes in design, lists only one alumnus prior to year 2000 out of a total 23 alumni (IIT Chicago, 2009). In India, the phenomenon is even more recent. Design research is carried out in a few institutes and only two institutes offer a PhD programme in design. These programmes have gained popularity within the last few years, with 10 and 26 students pursuing their PhD currently and with only 4 Design PhD alumni till date (IIT Guwahati, 2009), (IIT Bombay, 2009). A few more designers have either done or are doing their PhDs in an overlapping discipline in India.

This enthusiasm about design research and $\mathrm{PhD}$ is not shared unequivocally. There are sceptics in the design community who are not convinced about the value of research and PhD. They feel that research activities often take too much time and at the end, results are often predictable. Many practicing designers can't see the point. They allege a "sense of inferiority as designers and low self-esteem" as possible reasons (reference omitted in curtsey). Some also believe that the only valid reason to become a PhD could be to become a design teacher. Davis agrees that while the notion of design research culture does not seem odd to those outside the field, greatest scepticism about expanding design research programmes comes from designers themselves (Davis, 2008).

In this context it is important to try to answer the question - "Why do designers want to become PhDs?" "Not just to become an academic!" respond Jones and Jacobs (Jones, et al., 1998). But why, then? In an attempt to answer this question, I present a short survey that I conducted among designers perusing their $\mathrm{PhD}$ in India.

\section{METHOD}

A survey was created using the online survey tool SurveyMonkey.com. The questionnaire asked the respondents about their backgrounds. The first question was about the current status of my $\mathrm{PhD}$ (year 1, 2, 3, 4, 5+, recently finished and finished more than 2 years ago). The second question was about their educational background (undergraduate or masters) before $\mathrm{PhD}$ (design, engineering, architecture, visual arts, literary arts, other). A third question presented the statement "the best way to describe me is..." and gave the choices of

a designer who is doing a $\mathrm{PhD}$ in design, a designer who is doing a PhD in a design-related area (but not in design), a non-designer (engineer, architect, artist, other) doing a PhD in design, a non-designer (engineer, architect, artist, other) doing a PhD in a design-related area (but not in design), a designer doing a $\mathrm{PhD}$ in a designunrelated area, and none of the above.

Next, the survey asked about the motivation to start the PhD ("I started to do my PhD because...") and presented 5 Likert-scale type statements in a randomised order to which the respondent could agree or disagree with. The statements were "it is a requirement for a teacher in academic institutes", "I was interested in the area of my PhD", "I was interested in research", "I thought it will help me grow as a person" and "I thought it will improve my job prospects in the industry". It also had an open field for writing additional motivations not listed.

The last set of questions was about the impact of $\mathrm{PhD}$ on research, design, salary and on the person ("My PhD so far has helped me...") and presented 4 Likert-scale type statements in a randomised order to which the respondent could agree or disagree with. The statements were "become a better designer", "become a better design teacher", "become a better person" and "become a better researcher".

The effect of PhD on design ability, research ability and salary were gauged with three statements: "Instead of opting to do a PhD, had I continued what I was doing earlier, the quality of my design work at the end of my PhD tenure will be...", "...the quality of my research work at the end of my PhD tenure will be..." and "...my salary at the end of my PhD tenure will be..." with 5 choices ranging from "substantially worse than what it will be now" to "substantially better than what it will be now". There was an additional open field to describe other effects of $\mathrm{PhD}$ (either positive or negative).

\section{RESPONDENTS}

A list of potential respondents was created from student and alumni pages of websites of the two design schools that offer a PhD in Design in India and also by including all designers known to the author who have done a PhD or were doing one in another discipline. These respondents were invited to participate in the survey over email. A total of 34 people were invited. Among these, 20 people actually responded by filling out the online questionnaire. One other person declined to respond to the online questionnaire, but sent in some feedback on email.

Respondents were at different levels into their PhD. Among the 20 respondents, 7 had just joined their $\mathrm{PhD}$ (year 1), 2 in $2^{\text {nd }}$ year, 6 were in their $3^{\text {rd }}$ year, 3 in their $4^{\text {th }}$ year and one in $5^{\text {th }}$ year. One respondent had finished his PhD more than 2 years ago. Before their PhD, most respondents had a background in design (17/20), a few had 
backgrounds in visual arts (8/20), engineering $(6 / 20)$, and architecture (3/20). One participant had a background in literary arts and one in 'other'. (Participants could select multiple backgrounds to include undergraduate and masters levels of education.) Most respondents felt that the best way to describe them was "a designer who is doing a $\mathrm{PhD}$ in design" (8/20) or "a designer who is doing a $\mathrm{PhD}$ in a design-related area (but not in design)" $(7 / 20)$. Two people thought "a non-designer (engineer, architect, artist, other) doing a PhD in design" described them the best while two other people chose "a non-designer (engineer, architect, artist, other) doing a $\mathrm{PhD}$ in a design-related area (but not in design)". Interestingly, no one chose the option "a designer doing a PhD in design-unrelated area" though one person chose "none of the above".

\section{FINDINGS}

To the statement "I started doing my $\mathrm{PhD}$ because...", the overwhelming choice was "I was interested in the area of my PhD" (17/20 strongly agreed). "I thought it will help me grow as a person" (14/20 strongly agreed and another $3 / 20$ weakly agreed) and "I was interested in research" (12/20 strongly agreed and another 6/20 weakly agreed) also score well. All three are significant beyond $\alpha=$ 0.01 . Opinion was divided about the option "it is / will soon be a requirement for a teacher in academic institutes" and "I thought it will improve my job prospects in the industry". Neither are significant even at $\alpha=0.20$. (Figure 1 )

People were given an open field about mentioning any other reason for starting to do a $\mathrm{PhD}$, and some respondents left interesting, often emotional messages. Reasons mentioned included enjoyment, curiosity towards the research topic, sense of achievement, rigour of research and the need to reflect upon the world outside. In one case the PhD was initiated after inspiration from a mentor "I considered it as a blessing from someone who I respected a lot, and a great opportunity for me to evolve further". Another respondent vented his / her frustration about the rigidity of current education systems "our current UG level education doesn't allow one to even breathe" and "one is doubtful even about one's death". One person took up his PhD "not for any specific reason, but always want to do PhD". The PhD has helped many become a better researcher (13/20 strongly agreed, another $6 / 20$ weakly agreed, significant beyond $\alpha=$ $0.01)$, a better design teacher ( $9 / 20$ strongly agreed, another $5 / 20$ weakly agreed, significant beyond $\alpha=0.05)$ and also a better person (8/19 strongly agreed, 5/19 weakly agreed, significant beyond $\alpha=0.10$ ). Opinion was divided though tending towards positive about whether a PhD helped them become a better designer - though 4/19 strongly agreed and another 6/19 weakly agreed, the result is not significant at $\alpha=0.20$. (Figure 2)

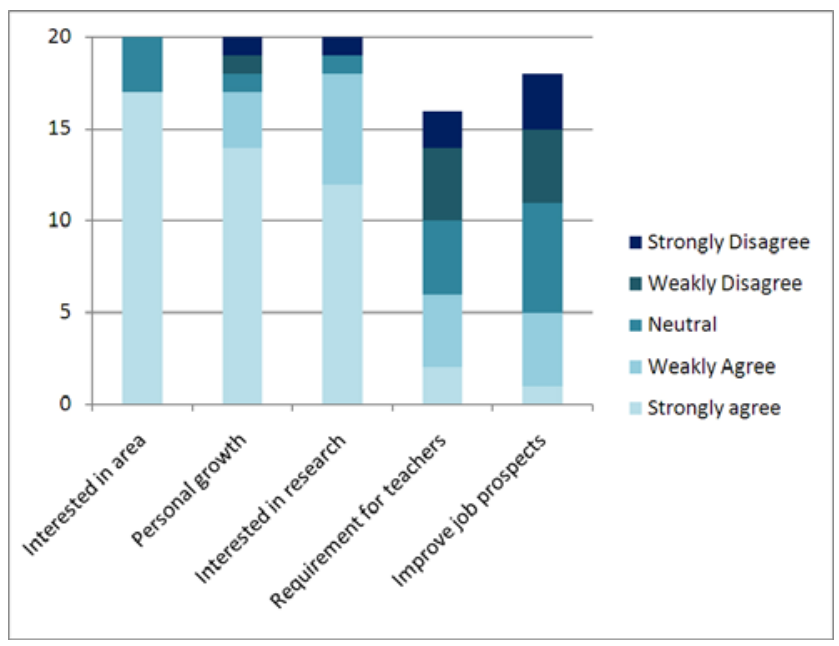

Figure 1: Why designers started to do a PhD.

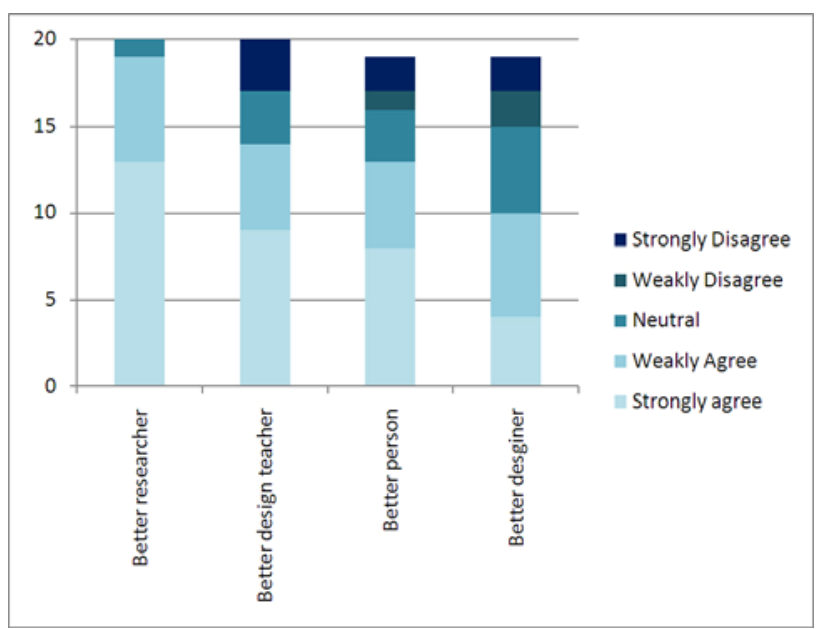

Figure 2: Effect of PhD on designers.

The effect on research is mildly positive - instead of opting to do a PhD, if they had continued to do what they were doing earlier, $45 \%$ believe that they would have been much worse off, and another $10 \%$ believe that they would have been a bit worse off in their research ability (significant beyond $\alpha=0.15$ ). Surprisingly, $\mathrm{PhD}$ has had very little effect on expected salary or ability to do design (neither are significant even at $\alpha=0.20$ ). In the free form text entry, respondents mentioned several good and bad effects of PhD. The bad things include financial difficulties, family issues, crankiness, time management problems, health toll and social isolation. One person mentioned, perhaps jokingly, "I've begun reading too much! Bad for the eyes!" The good points reflected the quantitative findings above, and seem to be strong motivators to overcome the difficulties. 
Related to professional development, respondents mentioned improved research skills and improved realisation of one's potential that one hadn't realised earlier. They also felt more determined to work in their area of work: "Though people have actually written to me about it, but I don't think i can give up researching the topic ever". The guide's role seems to be very important - one user mentioned: "I think I met a wonderful designer and human being, whom I can look up to in my guide. In fact he is one of the main reasons for my continuing interest in research."

There were many positive comments on the personal front, including a belief in one's convictions ("even if everyone else is against it"), passion, vigour, more tolerance of different point of views ("all are correct in their own way"), empowerment ("despite the hierarchical ranking in our society"), patience, calm, deep reflection and less impulsiveness. There was some feedback about the methodology of the questionnaire. One respondent stated that the question number $6,7,8$, 9 (about effect of $\mathrm{PhD}$ ) should have option "too early to say" as the questionnaire was close ended. The PhD student who had declined to respond to the questionnaire because he "did not warm up to answering them" raised questions "about the data that it can generate - and the conclusions that may emerge". But he did send an email describing the reasons why he was doing his $\mathrm{PhD}$, which may (perhaps against his wishes) be summarised as his interest in the area and an influence of his guide.

\section{CONCLUSIONS}

To the insiders of design research, perhaps the findings are obvious, but those on the periphery may be tempted to jump in and the sceptics may find some evidence against their arguments. The survey strongly establishes that the reasons why people do a PhD in design in India were interest in the research area, to grow as a person and general interest in research. The PhD has had much impact on individuals - it has helped people become better researchers, better design teachers and better people, but had no effect on their ability to design or their expected salary after PhD. Jones and Jacobs were right - there is no evidence that people are pursuing a $\mathrm{PhD}$ to become an academic, though there is some evidence that $\mathrm{PhD}$ helps in design teaching. There is also no evidence that a PhD is expected to lead to improved salary prospects. Free form comments reconfirm that $\mathrm{PhD}$ helps people in research abilities and in personality development and in their conviction to work hard, but also point to negative effects on finance, health and social behaviour. The deep involvement and impact of $\mathrm{PhD}$ guides was also notable. Like most quantitative surveys filled out in an online environment, this one also has its limitations (as was pointed out by one of the participants). It explains to an extent what happens, but lacks the subtler elements and an understanding of why things happen the way they do, though one can guess some of the reasons.

Qualitative depth interviews with individuals in various sub-domains at different stages of their $\mathrm{PhD}$ could throw more light on these issues and could be a matter of future investigations (or a topic for someone to pursue a PhD!).

\section{ACKNOWLEDGEMENTS}

I wish to thank all the respondents of the survey for their time and inputs.

\section{REFERENCES}

Archer, B. (1965) Systematic Method for Designers, Council of Industrial Design.

Bonsiepe, G. (2000) Design as a Cognitive Tool: The Role of Design in Socialisation of Knowledge, Design Plus Research, Milan, 2000.

Cross, N. (2007) Designerly Ways of Knowing. Birkhäuser, Basel.

Davis, M. (2008) Why Do We Need Doctoral Study in Design? International Journal of Design, volume 2.

Design Issues. (1984)

Design Studies. (1979)

IIT Bombay. (2009) PhD Students at IDC. http://www.idc.iitb.ac.in/students/phd.htm. (retrieved December 15, 2009).

IIT Chicago. (2009) Alumni. http://www.id.iit.edu/146/index.php?id=146\&type=P hD. (retrieved December 15, 2009)

IIT Guwahati. (2009) People in Research. http://www.iitg.ernet.in/design/researchers.htm. (December 15, 2009).

Jones, J. C., Jacobs, D. (1998) PhD Research in Design. Design Studies, volume 19, pages 5-7.

Journal of Design Research. (2001)

Newbury, D. (2002) Doctoral education in design, the process of research degree study, and the 'trained researcher'. Art, Design and Communication in Higher Education, volume 1, pages 149-159. 
PhD Design List. (1998)

https://www.jiscmail.ac.uk/cgi-

bin/webadmin?A0=PHD-DESIGN\&D=0\&T $=0$.

(retrieved December 15, 2009).

Ranjan, M.P. (2009) Design for India. http://designfor-india.blogspot.com/ (retrieved December 15, 2009).
Schön, D. (1983) The Reflective Practitioner: How Professionals Think in Action. Basic Books, New York.

Visible Language. (1967).

U\&lc. (1973) 